\title{
Presentación
}

\section{Apresentação dossier geografia dos transportes no Brasil}

Q Mónica Arroyo

Departamento de Geografía, Universidade de São Paulo - Brasil

\author{
Ricardo Castillo \\ Instituto de Geociências, Universidade Estadual de Campinas - Brasil
}

\begin{abstract}
A apresentação deste dossier chega exatamente 70 anos depois da publicação do livro de Moacir Silva Geografia dos Transportes no Brasil (Rio de Janeiro, IBGE/Conselho Nacional de Geografía, 1949), referência maior neste campo de estudos. Como observador atento das transformações que o Brasil experimentou nas primeiras décadas do século XX, Silva analisa o papel dos transportes na integração do território nacional. Considera a multiplicidade de fatores que condicionam o povoamento brasileiro à época, descreve os problemas e as dificuldades que enfrentam os modais de transporte bem como aponta soluções e possibilidades.
\end{abstract}

Sem a pretensão de abarcar o enorme leque de aspectos que esta temática envolve nos dias de hoje, os artigos que compõem o dossier desta revista oferecem ao leitor um panorama atual dos transportes no Brasil, considerando as características e contradições que a leitura do território evidencia. Com diferentes ênfases e ângulos complementares, os autores discorrem sobre as particularidades de cada modal: rodoviário de cargas, rodoviário de passageiros, ferroviário, aéreo, marítimo de longo curso e cabotagem; a mobilidade urbana também ganha destaque, sobretudo numa análise metropolitana.

A discussão sobre a cabotagem - uma das três categorias de navegação reunidas no modal aquaviário - foi realizada por Rafael Oliveira Fonseca no artigo intitulado $A$ navegação de cabotagem no Brasil: uma análise geográfica da conjuntura do modal no início do século XXI. Depois de ter desempenhado um papel protagonista na formação territorial brasileira em seus primeiros séculos, a navegação de cabotagem foi perdendo centralidade à medida que o modal rodoviário foi se consolidando, mormente em seus eixos longitudinais, sobretudo ao longo da segunda metade do século passado. No entanto, argumenta o autor, a reestruturação produtiva e territorial pela qual o país vem passando desde os anos 1990 encontrou na cabotagem uma função atrelada ao paradigma logístico que preside a circulação hegemônica de mercadorias. Os dados analisados por Fonseca sobre os investimentos do governo federal a partir da segunda metade da década de 2000 realizados no modal aquaviário, particularmente na indústria naval e nos portos organizados, bem como a colocação em prática da Lei de Modernização dos Portos aprovada na década anterior, comprovam de maneira consistente essa interpretação. Apesar da enorme diversidade de atividades produtivas e da quantidade 
exponencial de fluxos materiais internos ao território nacional, a cabotagem, hoje, inserida no paradigma da intermodalidade, se tornou bastante especializada, tanto do ponto de vista setorial (commodities minerais, destacadamente petróleo e bauxita) quanto geográfico, já que está restrita a poucos portos organizados e terminais de uso privativo, negligenciando dezenas de terminais ao longo dos milhares de quilômetros do litoral brasileiro.

O artigo de Nelson Fernandes Felipe Junior, por sua vez, apresenta um panorama atual do transporte marítimo de cabotagem e, sobretudo, do transporte de longo curso e do sistema portuário no Brasil. $\mathrm{O}$ texto, intitulado A dinâmica recente do transporte marítimo de cabotagem e longo curso no Brasil, mostra como o fomento do comércio exterior brasileiro e a maior diversificação das parcerias comerciais (fluxos Sul-Sul) principalmente entre 2003 e 2013 - geraram desdobramentos no transporte marítimo e no setor portuário nacional, com aumento da demanda por inversões em infraestruturas, maior movimentação de cargas, contêineres e navios nos portos brasileiros, modernização (investimentos em instalações, equipamentos e softwares), mudanças normativas e tributárias, aprimoramento da logística e da gestão, entre outros. $\mathrm{O}$ artigo também aborda as diferenciações existentes no sistema portuário das unidades federativas brasileiras, com uma grande concentração dos fluxos marítimos no Centro-Sul do país; apesar dessa tendência, o autor aponta que outros portos se destacam na última década principalmente para exportação de seus produtos, caso de Itaqui/MA (grãos e farelos) e Pecém/CE (combustíveis, grãos, frutas e carga geral). Outros aspectos são tratados, como políticas e ações do Estado brasileiro no setor portuário e de infraestrutura bem como a atuação de grandes empresas e as fusões e aquisições recentes no setor marítimo; discute-se a importância do planejamento e apontam-se propostas para fomentar o sistema portuário no Brasil.

Uma análise histórica de caráter revisionista do sistema ferroviário brasileiro foi formulada por Ivanil Nunes, em seu artigo Do público ao privado: a transição do modelo de negócios ferroviários no Brasil, 1930-2015. A hipótese defendida pelo autor postula que o sistema ferroviário brasileiro não passou por um processo de desmontagem a partir da década de 1940, como alegam autores clássicos que se dedicaram a estudar o modal, dos quais alguns chegaram, inclusive, a decretar o fim da "era ferroviária". De acordo com Nunes, sobretudo no momento em que todas as empresas do setor eram operadas pelo Estado (entre 1961 e 1990, segundo a periodização adotada), o que ocorreu foi uma racionalização do uso da malha ferroviária, com supressão de ramais antieconômicos e desativação de serviços menos produtivos ou mesmo deficitários, como o transporte de passageiros, bagagens, encomendas e animais. Bem antes da privatização das ferrovias, portanto, a RFFSA e outras companhias ferroviárias controladas por estados já vinham se transformando em empresas dedicadas ao transporte de cargas. Portanto, o que de fato ocorreu foi uma mudança dos negócios ferroviários, de um padrão de produção múltipla, no qual um grande leque de serviços deve ser prestado e horários rígidos obedecidos, para um padrão de "ferrovia mínima" (ou produção simples), mais flexível, especializado no transporte de carga, mais seletivo em termos de setores atendidos (minérios, petróleo, siderúrgicos e cimento constituem a quase totalidade dos produtos transportados), de clientes (grandes embarcadores, como a Petrobrás e a Companhia Vale do Rio Doce) e de linhas utilizadas (as mais rentáveis). Todo esse processo teria levado ao aumento da produtividade do sistema ferroviário brasileiro, tornando-o atrativo aos capitais privados. A evidência mais contundente desta hipótese teria sido o processo de privatização de todo o sistema ferroviário na década de 1990.

Ana Paula Camilo Pereira e Hervé Théry encarregaram-se, neste dossiê, de discutir o sistema aeroviário brasileiro, no artigo intitulado Topologia das linhas aéreas no Brasil: novas lógicas do poder territorial, com foco nas causas e nas estratégias de redefinição da topologia das linhas das principais empresas que atuam no mercado aéreo doméstico. 
Depois de traçar um panorama histórico sobre a ascensão e queda do poder territorial da companhia Varig, com direito a uma rica cartografia da evolução topológica da empresa, os autores abordam as estratégias territoriais das quatro grandes empresas aéreas da atualidade (Latam, Gol, Azul e Avianca) e a redefinição da topologia de suas malhas aéreas a partir dos principais hubs aeroportuários do país (Congonhas-SP, Cumbica-SP, Viracopos-SP, Galeão-RJ, Santos Dumont-RJ e Brasília-DF). O papel da companhia aérea Azul ganha destaque, uma vez que esta empresa consolida um novo hub aeroportuário (Campinas, SP) e diversifica suas linhas aéreas para lugares negligenciados por causa da menor densidade de passageiros e cargas, constituindo a maior malha aérea regional da América Latina, inclusive operando voos regionais fora da chamada Região Concentrada. Um dos argumentos centrais de Pereira e Théry é justamente que, a partir da estratégia competitiva da Azul de valorização dos voos regionais, as demais empresas atuantes no mercado nacional também redefiniram suas lógicas territoriais, gerando uma reorganização mais abrangente das linhas aéreas no país. Trata-se, de acordo com os autores, de uma nova lógica do capital em sua relação com o uso do território, em diferentes escalas geográficas.

O transporte rodoviário é central na matriz brasileira e Daniel Monteiro Huertas mostra muito bem isto no seu artigo intitulado Breve análise espacial dos fluxos origem-destino do transporte rodoviário de carga. $\mathrm{O}$ autor realiza uma análise espacial dos fluxos do transporte rodoviário de carga a partir dos dados da Pesquisa Nacional de Tráfego 2011, elaborada pelo Ministério dos Transportes, que corresponde a uma matriz origemdestino com caminhões vazios e com carga. Um dos pontos considerados é a participação de cada agente (empresa transportadora; caminhoneiro autônomo agregado e/ou independente) no total da circulação e sua escala de atuação no território. A análise dos dados da PNT 2011, sob o ângulo da dinâmica regional, permite observar fenômenos como a relevância do transporte intraestadual e o papel central do estado de São Paulo no âmbito nacional. Huertas sistematiza a informação separada para cada macrorregião, e para cada unidade da Federação, do número total de caminhões registrados e das principais origens e principais destinos da carga. Destaque especial para o frete-retorno, considerado pelo autor como uma das variáveis que melhor revela o desequilíbrio entre pontos de consumo, de produção e na relação entre ambos; a volta vazia é um problema a ser enfrentado por todos os agentes. Além da perspectiva analítica, o autor assinala algumas deficiências na matriz origem-destino do transporte rodoviário de cargas, apontando que estas pesquisas não captam a variável operacional do serviço (carga lotação ou fracionada) e as operações de transferência e transbordo de carga, fato que compromete a análise em um país de dimensões continentais e regionalmente bastante desigual.

Bruno Cândido dos Santos discute o transporte rodoviário de passageiros no seu artigo intitulado Divisão territorial do trabalho, rede urbana e transporte rodoviário interestadual de passageiros no Brasil. De um país com população predominantemente rural a um território com maioria populacional urbana, o transporte rodoviário de passageiros permitiu o deslocamento de milhões de pessoas para pontos diversos no Brasil, sendo peça central em um cenário de intensos fluxos migratórios ocorridos na segunda metade do século passado. Com base nesta constatação histórica, o autor destaca a importância que ainda mantém este modal de transporte, relativamente pouco estudado. Ainda existem linhas com mais de 2 mil quilômetros de extensão, que atendem a dezenas de cidades, em percursos que duram mais de 40 horas, pois para parte considerável da população, com renda mais baixa, ainda são a única opção de transporte coletivo. No debate atinente à regulação da atividade, o transporte interestadual rodoviário passou a ser operado pelo regime autorizatário, no qual as autorizações para as linhas interestaduais têm um prazo de duração de três anos, e podem ser renovadas desde que a transportadora respeite algumas especificações operacionais. Assim, o regime autorizatário confere maior flexibilidade ao setor, pois difere das concessões e permissões que 
perduram por prazos mais longos; as autorizações facilitam a distribuição das linhas entre as companhias, beneficiando geralmente os grandes conglomerados. $\mathrm{O}$ artigo também mostra como, quando são analisados os dados de demanda por município, unidade federativa ou linhas, algumas porções do território nacional se sobressaem, evidenciando a correspondência com a divisão territorial do trabalho, sua dinâmica histórica e atual.

Os constrangimentos da mobilidade na metrópole de São Paulo é o título da contribuição de Ricardo Barbosa da Silva para este dossiê da RTT. Sua atenção está voltada para a crise da mobilidade cotidiana na Região Metropolitana de São Paulo, buscando contribuir para a sua compreensão através da análise da divisão modal (transporte coletivo, transporte individual e viagens não motorizadas), dos motivos (trabalho, educação, compras, saúde, lazer) e dos tempos dos deslocamentos. Ao longo de uma análise realizada com o respaldo de diversas bases de dados, principalmente da pesquisa origem / destino, o autor constata, no período de 1997 a 2012, uma queda da velocidade média geral do transporte motorizado no município de São Paulo e um tempo maior de deslocamento no modo coletivo (em média, praticamente o dobro do modal individual). O expressivo aumento do número de automóveis tem um papel central na explicação desse fenômeno, que já ultrapassa a porção central da região metropolitana e atinge algumas de suas áreas periféricas.

André Baldraia, em seu artigo intitulado Um passo atrás para poder dar dois passos adiante? Considerações sobre as políticas de mobilidade urbana no município de São Paulo cinco anos após a vigência da Política Nacional de Mobilidade Urbana Sustentável (PNMU), discute algumas das transformações nos sistemas viário e normativo pelas quais passou a capital paulista a partir da implementação, ainda que parcial, do Plano Municipal de Mobilidade Urbana, aprovado em 2015, como resposta local à Lei 12.587 de 2012, que estabelece a Política Nacional de Mobilidade Urbana. Em meio à extrema complexidade geográfica do município de São Paulo, decorrente da crescente distância absoluta e relativa entre polos geradores de emprego e áreas de maior densidade populacional, o autor demonstra como a cidade se tornou refém de intensos fluxos casa-trabalho e trabalho-casa e do aumento do transporte individual motorizado como causa e consequência da precariedade do transporte público coletivo. Baldraia argumenta que o Plano Municipal representou um importante avanço na solução do problema de mobilidade cotidiana, através da valorização do modal cicloviário, do programa Ruas Abertas, das faixas exclusivas para ônibus e da redução da velocidade máxima em vias estratégicas da cidade. O Plano, pautado no paradigma da dimensão humana e na denominada mobilidade ativa, sofreu um revés em 2017, quando a nova administração municipal desmonta parcialmente as políticas públicas implementadas e sinaliza para a volta de um paradigma de mobilidade urbana que privilegia os modais motorizados e o transporte individual.

Por fim, a mobilidade urbana também é tema do artigo de Rodrigo Giraldi Cocco, intitulado A reprodução de velhos paradigmas em politicas de transporte e mobilidade: uma análise da Região Metropolitana de Florianópolis. $\mathrm{O}$ autor discute como premissa central a relação entre as especificidades do espaço construído e do quadro físico da Região Metropolitana de Florianópolis, que conferem grande complexidade à região, e a falta de instituições de planejamento metropolitano capazes de operar de modo eficaz e inovador em meio a essa complexidade. São entraves na esfera político-econômica e institucional que, conforme sua avaliação, acabam inviabilizando ações de planejamento mais contundentes. Dados referentes à expansão da frota de automóveis indicam que, entre 2002 e 2017, houve em Florianópolis crescimento da frota de automóveis acima de outras regiões metropolitanas brasileiras, mostrando um crescimento urbano que exige o automóvel para a realização das atividades cotidianas e evidenciando um amplo domínio do uso do transporte individual privado em detrimento dos demais modos. 
Problemas como o caráter desintegrado dos sistemas de transporte público e os altos tempos de deslocamento resultam da desintegração institucional no planejamento e na gestão regional da mobilidade.

A riqueza das análises e reflexões presente no dossier revela a importância deste campo de estudos na geografia contemporânea e indica um caminho fértil de pesquisas a ser trilhado. O transporte é visto aqui, não como uma variável autônoma ou isolada da formação sociespacial, mas como uma variável associada, isto é, que se explica nas instâncias econômicas, políticas e espaciais e nas suas determinações históricas. Esperamos que novos estudos venham a se somar a este esforço.

\section{Mónica Arroyo / mmarroyo@usp.br}

Professora do Departamento de Geografia da Universidade de São Paulo e Pesquisadora do CNPq. Doutorado em Geografia pela Universidade de São Paulo. Mestrado em Integração da América Latina pela Universidade de São Paulo. Graduação em Geografia pela Universidad de Buenos Aires. Tem experiência na área de Geografia, com ênfase em Geografia Econômica, Geografia Regional, América Latina, Circulação.

\section{Ricardo Castillo / castillo@unicamp.br}

Professor do instituto de Geociências da Universidade Estadual de Campinas e Pesquisador do CNPq. Graduação, mestrado e doutorado pela Universidade de São Paulo, com estágio na Universidade de Paris I - Panthéon-Sorbonne. Tem experiência na área de Geografia, com ênfase em Análise de Redes de Fluxos (Transportes e Logística), Geografia Agrária e Geografia Regional. 